\title{
Effects of ultra-sonication on the cyanobacteria Microcystis aeruginosa structure and growth
}

\author{
H. Muelle*, P. Barquinha ${ }^{* *}$, I. Ferreira $^{* *}$, E. Fortunato ${ }^{* *}$, M. Conceição Santos ${ }^{*}$ and M.S. Diniz ${ }^{* * *}$
}

*Faculdade de Ciências e Tecnologia, Universidade Nova de Lisboa -Departamento de Ciências e Engenharia do Ambiente. Quinta da Torre - 2829-516 Caparica, Portugal

*** CENIMAT/I3N e Departamento de Ciências dos Materiais, Faculdade de Ciências e Tecnologia, Universidade Nova de Lisboa, Quinta da Torre, 2829-516 Caparica, Portugal

***REQUIMTE, Departamento de Química, Faculdade de Ciências e Tecnologia, Centro de Química Fina e Biotecnologia, Universidade Nova de Lisboa, 2829-516 Caparica.

e-mail: $\underline{\text { mesd@fct.unl.pt }}$

The eutrophication of surface waters caused by cyanobacteria is a worldwide problem, leading to expensive water treatment costs [1]. In addition, the production of microcystins by these microalgae may cause many health problems to humans and animals (e.g. liver cancer) and even death [2]. Therefore, a variety of methods have been developed to control cyanobacteria blooms, including physical and chemical treatments. However, they have negative impacts on other species of (micro) algae and on other aquatic biota. As a consequence, ultrasonic algae treatment has been proposed as a clean approach to controlling the blooms of some algae species and microcystins degradation [3]. Still, the specific effects of ultra-sonication on cyanobacteria are not well known. The present work aimed to study the effects of ultra-sonication on the cyanobacteria structure under different ultrasound conditions (changing frequency and power) by using conventional histology and electron microscopy methods.

Microcystis spp. were harvested in a lake from Azores (Portugal) and stored in the cool and dark until transported to the laboratory. Cyanobacteria were cultured in liquid BG-11 axenic medium at $22^{\circ} \mathrm{C}$ in an incubator chamber, under continuous illumination (fluorescent cold white light).

Samples were collected and suspensions of cells $(1 \mathrm{ml}$ each) were subjected to ultrasonic irradiation using diverse ultrasonic equipment (UP100H; UP200S, sonoreactor UTR 200 and ultrasonic bath) and testing different exposure times. All the experimental algal suspensions were exposed for 5 min to ultrasonication (on ice for periods of 10s to avoid heating). After ultrasonication cyanobacteria growth was assessed for a period of 14 days and structural changes in cells were evaluated by light (LM) and scanning electron microscopy (SEM) examination. The results show growth inhibition of the cyanobacteria according to intensity and power used in each ultrasonic device. The use of the most powerful devices (sonoreactor and UP200S) resulted in a massive disrupting of cell walls with consequent cell death (Fig. 1e,f). Similar results were obtained by Ahan et al. [1] and Nakano et al. [4] and showing cell wall disruption. However, even after exposure to the most powerful instrumentation it was possible to detect some viable cells and after 14 days colonies were already visible. The results from light and electron microscopy showed noticeable changes at the structural level such as disruption of cell gas vacuoles (arrowhead), colony disaggregation and damage of cell walls of cells (Fig. 1c-f).

As a consequence, the use of ultrasounds to improve water quality from eutrophic waters must be considered with careful in terms of efficiency and other complementary methods should be considered to assure good water quality criteria. In addition, the effects of ultrasonication in other aquatic organisms require further studies before using this technology to control algae blooms. 
The authors acknowledge the funding by Fundação para a Ciência e Tecnologia through project no. PEstC/EQB/LA0006/2013 granted to Requimte.

[1] Ahn, C-Y. et al., Environ Sci Technol, 37, 3031-3037, 2003.

[2] Hao, H. et al., Environm Sci Health Part A, 6, 1435 - 1446, 2004.

[3] Zhang, G. et al., Ultrasonics Sonochemistry, 16, 334-338, 2009.

[4] Nakano, K. et al., Environ Sci Technol, 35, 4941-4946, 2001.
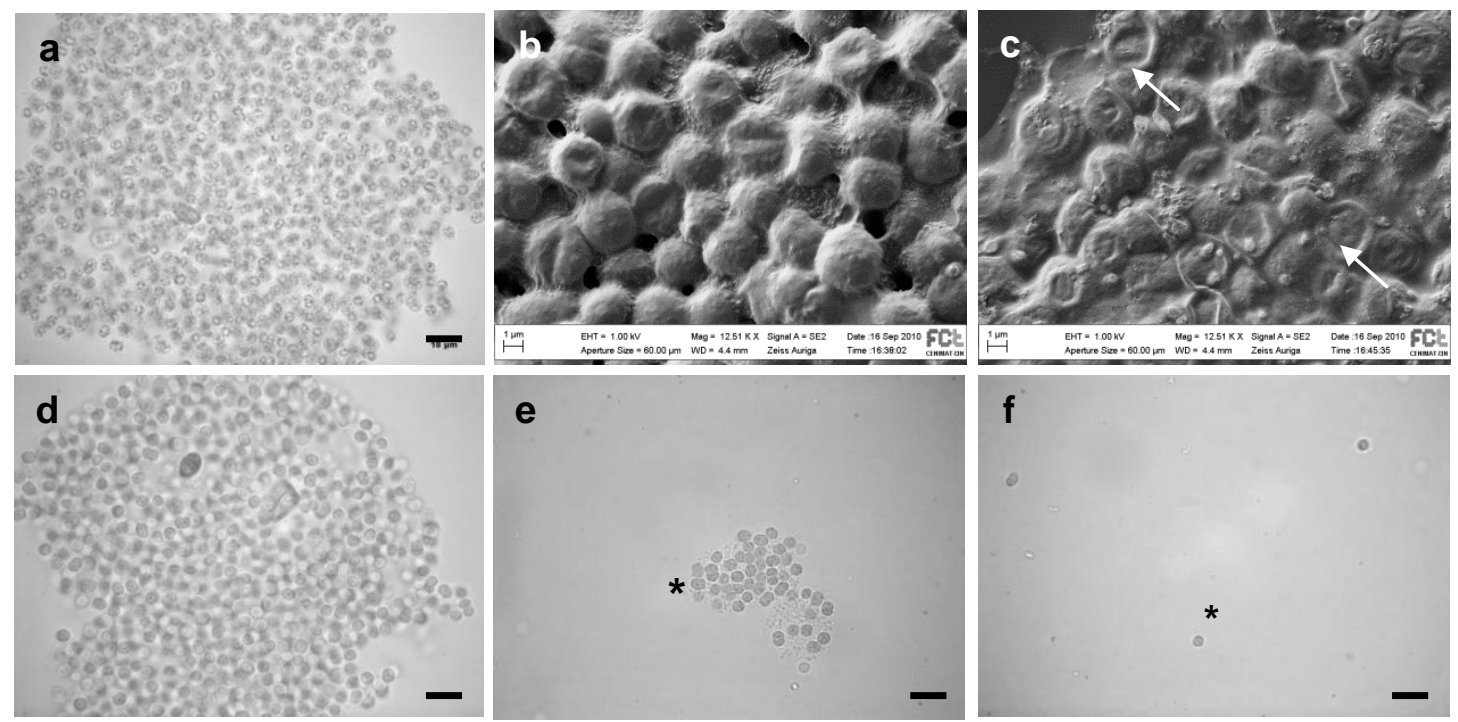

Figure 1: representative pictures of the effect of ultrasonic irradiation (power 100\%) in Mycrocistis spp. exposed to different frequencies (kHz) and according to the type of devices used. Legend: (a) control (LM), (b) control (SEM), (c) $130 \mathrm{KHz}$ US bath (SEM), (d) $25 \mathrm{KHz}$ US bath ultrasonic probe (LM), (e) $24 \mathrm{KHz}$ UP100H ultrasonic probe (LM); (f) $24 \mathrm{KHz}$ sonoreactor (potency 20\%). Arrowhead: cell disruption; $(*)$ M. aeruginosa . Bar $=10 \mu \mathrm{m}(\mathrm{a}, \mathrm{d}, \mathrm{e}, \mathrm{f}) ; \mathrm{Bar}=1 \mu \mathrm{m}(\mathrm{b}, \mathrm{c})$. 